\title{
Interactive Virtual Reality Cognitive Learning Model for Performance Evaluation of Math Manipulatives
}

\author{
Lamya Daghestani ${ }^{\mathrm{a}, \mathrm{b}}$, Hana Al-Nuaim ${ }^{\mathrm{a}}$, Zhijie $\mathrm{Xu}^{\mathrm{b}}$, \\ Abdul Hamid M. Ragab ${ }^{\mathbf{a}}$ \\ ${ }^{a}$ Faculty of Computing and Information Technology, King Abdulaziz \\ University, Jeddah, Saudi Arabia. ${ }^{b}$ School of Computing and \\ Engineering, University of Huddersfield, Huddersfield, United Kingdom \\ lamya.daghestani@gmail.com, alnuaimh@yahoo.com,z.xu@hud.ac.uk, \\ ahm_ragab@yahoo.com
}

\begin{abstract}
Applications of virtual reality in E-Learning are gaining more popularity due to its interactive characteristics of virtual environments that can be offered. One unique example of this application is the use of virtual manipulatives, since they can be implemented on PCs economically for teaching students interactively in schools and universities. They enable students to learn mathematics thoroughly by easily providing computer-generated dynamic objects, allowing them to explore abstract mathematical concepts in a handson mode experince. In this paper, an implemented virtual reality based math virtual manipulatives is presented. A cognitive virtual reality learning model is also introduced. Performance evaluation of the virtual manipulatives, for several case studies, is achieved. Comparisons between the 2- Dimensions (2D) Java applets from National Library Virtual Manipulatives (NLVM) and the developed Java 3D Virtual Reality Math Manipulatives (VRMM) cases are performed. Results of the practical analysis for student grades show that VR enhances student learning of addition and subtraction operations in the VRMM, and it achieves superior results than the NLVM.
\end{abstract}

\section{Introduction}

Virtual Reality (VR) environments can be described as a multisensory, highly interactive computer environment that makes the user 
believe that he/she is actually experiencing a situation even though they are, in reality, participating in an artificial environment ${ }^{[1]}$. VR environments are developed to support learning for a variety of skills. VR has been applied successfully across a wide range of application domains, providing new ways of visualizing, manipulating and interacting with objects, where VR helps to improve performance and conceptual understanding on a variety of disciplines-from science ${ }^{[2]}$ and humanities $^{[3]}$ to social studies ${ }^{[4]}$, medicine ${ }^{[5]}$, and training ${ }^{[6]}$. Crosier et $a l .{ }^{[7]}$ noted that there are several characteristics or attributes that set VR environments as being a unique and potentially very useful educational technology; these are as follows: Visualization and manipulation, feel of presence afforded by free of navigation and real time interaction, 3D representation of abstract concepts. Even non-immersive VR such as desktop VR environments, can induce users to feel a sense of presence having monitor-based viewing of $3 \mathrm{D}$ objects on a normal computer screen and manipulated using mouse and keyboard ${ }^{[8]}$.

Most existing VR systems for education are based on the constructivist learning theory, which assumes that the students construct their own understanding of what they study while they interact within the VR environments. It is suggested that VR facilitates new kinds of learning experiences that are highly perceptual in nature, and which enable the students to be immersed within a phenomenon that is visual in nature. The idea is that students are better able to master, retain and generalize new knowledge when they are actively involved in constructing the knowledge through learning-by-doing, as this paper explains.

This paper introduces the work related to Virtual Reality Math Manipulatives (VRMM) which is implemented using Java and Java 3D Application Programming Interface (API). An Interactive Learning VR Cognitive Model is introduced. A cognitive theory of virtual reality learning model is also presented. Performance evaluations of the virtual manipulatives results are performed. Comparisons case studies are tackled between VRMM and NLVM 2D Java applets from (http://nlvm.usu.edu/). Results show superiority of the VRMM, as will be discussed in details. 


\section{Virtual Manipulatives Overview}

Virtual Manipulatives (VM) are defined as a computer-generated or Web-based dynamic objects that allow students to explore abstract mathematical concepts in a hands-on mode, which presents opportunities for constructing mathematical knowledge for enhancing teaching and learning mathematics ${ }^{[9,10]}$. Working with math VM help students move from the concrete to the conceptual, so they can better understand abstract and symbolic ideas ${ }^{[11]}$. VM are often dynamic visual/pictorial replicas of commonly used physical manipulatives like pattern blocks, base-10 blocks etc ${ }^{[12]}$. They are used effectively in facilitating students' understanding of mathematical concepts, positive results appear to be due to the visual nature of these manipulatives and students' ability to use them interactively ${ }^{[13,14]}$.

An investigation by Bolyard and Moyer-Packenham ${ }^{[15]}$ on the impact of 2D math VM named NLVM on student achievement in integer addition and subtraction was carried out. The general conclusion stated that the VM environments supported students' learning of these concepts. Yun et $a l .{ }^{[16]}$ developed a virtual game-based learning environment (VGBLE) used for learning addition and subtraction operation for one digit numbers. VGBLE is designed by combining Virtual Reality Modeling Language (VRML) with 3D max modeling tools and Java Script Authoring Interface (JSAI) for interaction in VRML scenes. Through experiments, the author found that students' learning interest and attention are improved. In Daghestani et al. ${ }^{[17]}$ a Mathematical Virtual Learning Environment (MAVLE) is a standalone prototype application implemented using Java 3D. It used for learning addition operation. The preliminary results suggest that several students specified that they felt immersed in the environment, even though no special immersive VR hardware was used.

In Figueira-Sampaio et al. ${ }^{[18]}$, a virtual balance environment is developed; it allows the concepts and procedures of mathematical algebra equations in elementary schools to be represented in a VR environment. An interactive immersive VR environment by Roussou ${ }^{[19]}$ was developed specifically for fractions in mathematics. Conclusion suggested that students who fully interacted with the VR environment are able to problem-solve but that there was no strong evidence of the expected conceptual change. An enhanced version of MAVLE was developed in 
Daghestani et $a l . .^{[20]}$, showing that students interacting with MAVLE significantly outperformed the students interacting with NLVM. In this paper we extend the previous work of Daghestani et al. ${ }^{[20]}$ to include several other case studies.

\section{Virtual Reality Math Manipulative (VRMM)}

The VRMM system was designed and developed for young children to practice and exercise numeracy concepts (addition and subtraction). The researcher built and tested a VRMM using Java and Java3D API development of 3D graphics. Java3D is a more exclusive tool for creating customised 3D graphical applications. The VRMM system runs on a standard Intel PC hardware platform under MS Windows XP operating system ${ }^{[20,21]}$.

Fundamentally, constructivism asserts that the student learns through a continual process of constructing, interpreting, and modifying his own representations of reality, based on his experiences with reality $^{[22]}$. Jonassen and Tessmer ${ }^{[23]}$ proposed that learners need to develop learning strategies that induce the learner to:

- Active learners to engage in interaction with and manipulation of the exploration environments that we construct. In VRMM this is achieved using the keyboard and mouse, performing selections.

- Exploratory learners to strategically search through these environments. In VRMM this achieved by using VR navigation characteristics (such as Walk, Fly, and Study).

- Intentional learners willingly trying to achieve cognitive objectives. In VRMM this is achieved by rehearsal.

- Conversational learners engaged in dialogue with other learners and with instructional systems. In VRMM the only dialogue is achieved between the PC and the learner using sound feedback that alert the student when performing illegal actions, or sound alert for attention while the student is dropping base-10 blocks to represent the exercises.

- Reflective learners articulating what they have learned and reflecting on the processes and decisions that were included in the process. This supported in VRMM by using the Glue icon in order to 
perform the carry operation, or while using the Hammer icon in order to perform the borrow operation.

- Ampliative learners who generate assumptions, attributes and implications of what they learn and 'extend' the information given.

- Ampliative student can enlarge a conception by adding to that which is already known or received.

\subsection{VRMM Operations}

Dienes-Blocks manipulatives are used. It is believed that the Dienes blocks (also known as base-10 blocks) were developed by the Hungarian Mathematician Dr. Zoltan Paul Dienes, and were nvented to teach place value [24]. The virtual manipulatives available in VRMM are the standard Dienes-Blocks manipulatives. Base-10 blocks are used in many classrooms today and they are (see Fig. 1):

- Unit=1-block, used to represents numbers at the 1's place-value

- $\operatorname{Rod} /$ Long $=10$-block, used to represents numbers at the 10 's place-value

- Flat $=100$-block, used to represents numbers at the 100 's placevalue

- Cube $=1000$-block, used to represents numbers at the 1000's place-value

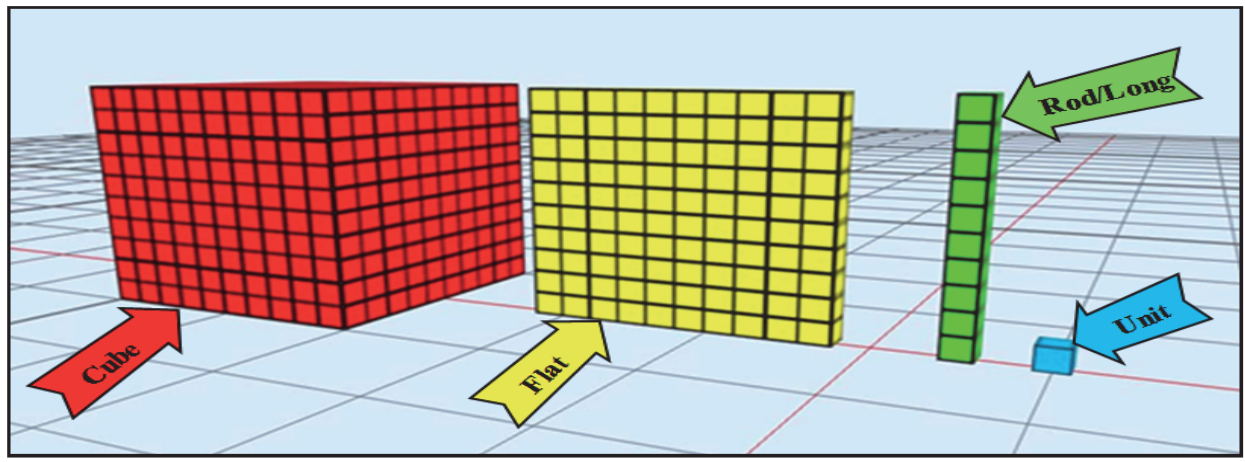

Fig. 1. VRMM base-10 block virtual manipulatives.

The interactive operations that can be achieved using VRMM are shown in Fig. 2. These operations are performed as follows: 


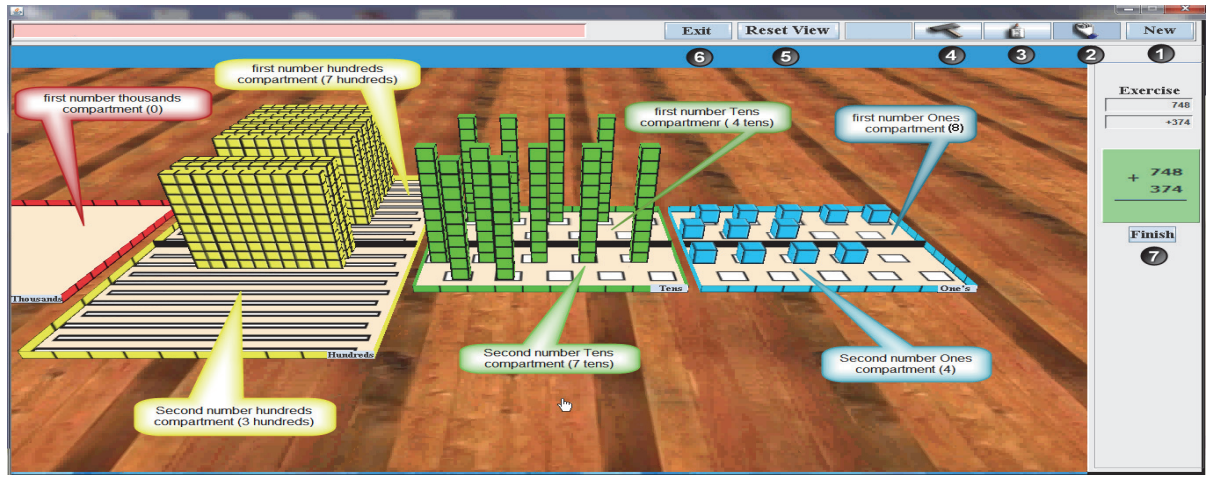

Fig. 2. VRMM screen shot for operations.

1. Clicking on this 'New' button will Start new exercise dialog box.

2. The 'Hand' icon used to put VRMM in normal mode which is the most common one. This is the mode where students can perform interaction tasks ('drop' new base-10 block inside any compartments in order to represent the required new exercise numbers, also used to select, drag and pick base-10 blocks.

3. The 'Glue' icon used to align 10 base-10 blocks in a straight line to be glued together to form the corresponding upgraded place value.

4. The 'Hammer' icon does the opposite of what the Glue does. This hammer is used to break base-10 block (Tens, Hundreds or Thousands) into the next lower place value.

5. The 'Reset View' button used to reset VRMM view to the initial screen view.

6. The 'Exit' button used to exit from VRMM.

7. The 'Finish' button used to check the final result in written number.

\subsection{VRMM Interaction Tasks}

The VRMM interaction tasks are achieved using standard mouse and keyboard. These interaction tasks are shown in Fig. 3. They include four tasks as follows:

1. Navigation: The navigation inside the VRMM is accomplished using standard keyboard and mouse as follows:

- Click right mouse button + drag side way left/right in order to move along $\mathrm{X}$ axis. 
- Click right mouse button + drag up/down in order to move along $\mathrm{Y}$ axis.

- Roll mouse wheel forward/backward in order to move along Z axis.

- Press keyboard up/down arrows in order to turn up/down around $\mathrm{X}$ axis (Pitch).

- Press keyboard left/right arrows in order to turn left/right around $\mathrm{Y}$ axis (Yaw).

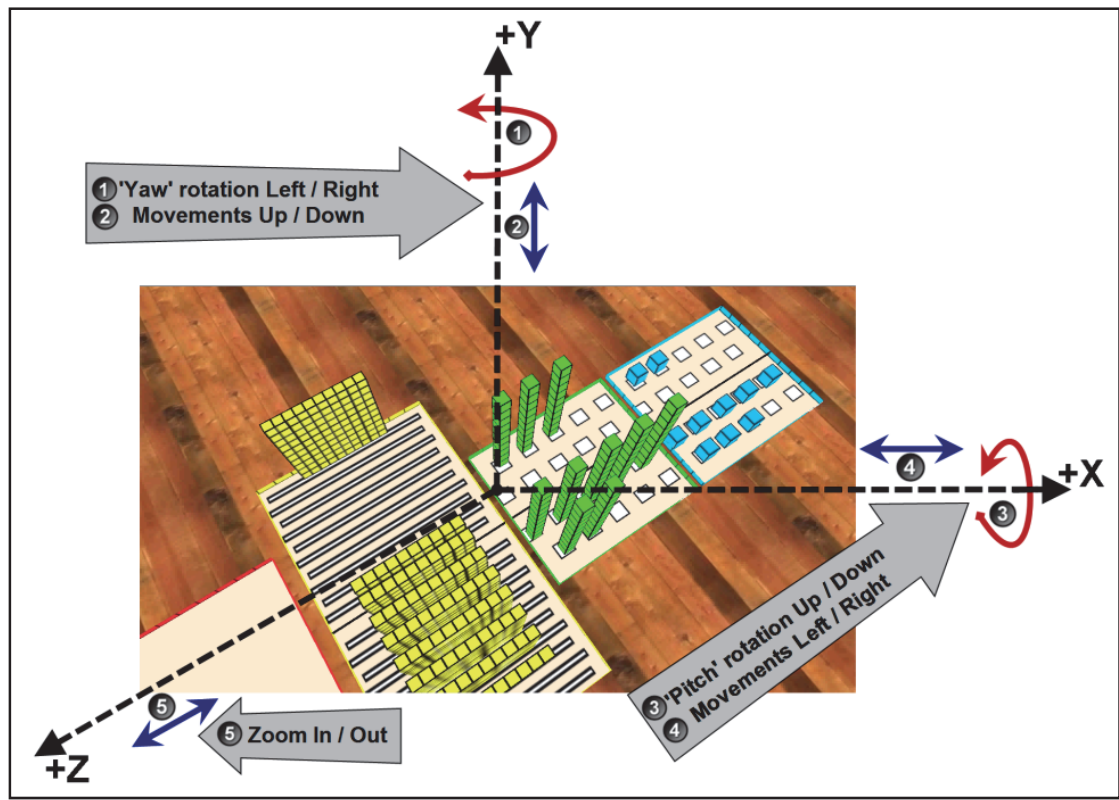

Fig. 3. VR navigations within VRMM.

2. Selection: to handle two tasks

- Picking: To pick a base-10 block 'Click Mouse Left Button'.

- Move: To move base-10 block 'Click and Drag Mouse Left Button'.

3. Manipulation: Pressing the mouse middle button inside any place value compartments will drop base-10 block as much as the exercises request. The buttons on the top panel such as: Hand, Glue bottle, and Hammer will help user to manipulate within VRMM so he/she can move the base-10 block, or glue and break base-10 block from 
one compartment to another. However, errors of manipulation are considered as warnings and implemented as a 'Ping sound'.

4. System Control: To handle the following tasks:

- Base-10 block dropped in predefined places, in each compartment is indicated by a specific sound.

- Collision Detection: Base-10 block vs. Base-10 block and Base-10 block vs. Compartment separators (illegal movements) are denoted by a specific sound.

- Gluing the final Base-10 block to form a set of 10 is indicated by a specific sound during the carry operation

- Hammering to break a set of Base-10 blocks indicated by a specific sound during the borrow operation

- Each compartment can hold only 10 Base-10 blocks. The user can not add additional base-10 block; instead a warning will be issued (a ping sound).

\section{Interactive Learning VR Cognitive Model}

An interactive learning cognitive model, as shown in Fig. 4 is proposed. The positioning and orienting of sensory organs are initial preprocessing of perception data ${ }^{[25]}$. The key properties that underline the development of interactive learning cognitive model are the three sensory organs channels: Eyes (for seeing images), Ears (for hearing sounds), and Hands (for handling interactivity tasks). The selected perceptions are then processed and transformed into the working memory. These transformations are performed using prior knowledge contained in the long-term memory ${ }^{[26]}$. The products of this processing in the working memory represent temporary mental models structures such as (auditory, pictorial, and perceptual). Mental models are then encoded to form new knowledge that is stored in long-term memory ${ }^{[21]}$. The accumulated knowledge (prior-knowledge + new-knowledge) in long-term memory determines our perceptions. At the same time, our interpretation of sensory perceptions requires retrieval from long-term memory ${ }^{[27]}$. Thereby, the rehearsal perceptions from long-term memory affect the short-term memory by the hands interactivity (selecting, manipulating, or moving). 


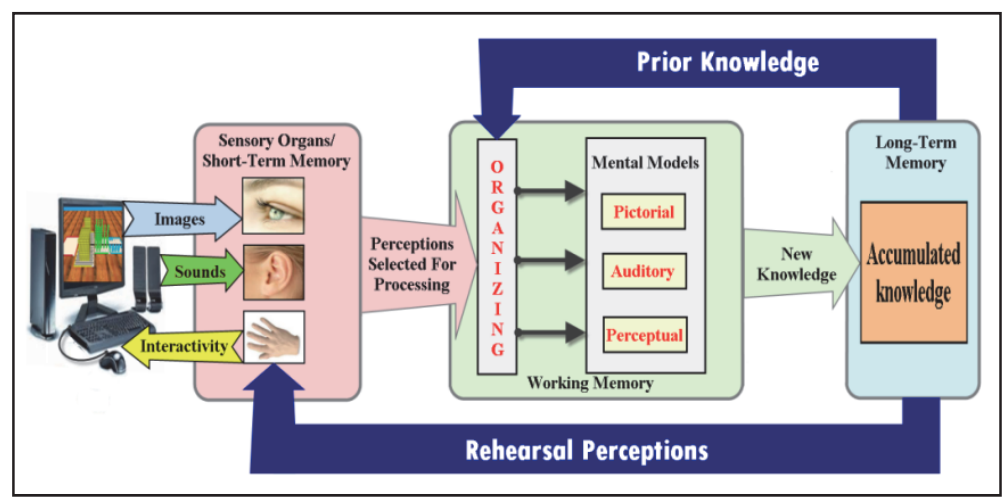

Fig. 4. Interactive learning cognitive model.

\section{Comparison between Multimedia Learning Cognitive Model and VR Model}

In this section, a comparison between Mayer's cognitive theory of multimedia learning model and the proposed VR cognitive model is presented.

\subsection{Cognitive Model of Multimedia Learning}

Cognitive theory offers three theory-based assumptions about how people learn from words and pictures: the dual channel assumption by Paivio ${ }^{[28]}$, the limited capacity assumption by Sweller ${ }^{[29]}$, the active processing assumption by Mayer ${ }^{[30]}$. Mayer's ${ }^{[30]}$ cognitive theory of multimedia learning takes place within two separate information processing systems: a visual system for processing visual knowledge and a verbal system for processing verbal knowledge as shown in Fig. 5. According to this theory, the computer is a system for delivering information to learners. The instructional designer's role is to present information (e.g., as words or pictures, or both) and the learner's role is to receive the information.

The cognitive information processes stated by Mclaren et al. ${ }^{[31,32]}$ includes: "selecting relevant information, mentally organizing it into a coherent structure, and integrating it with other knowledge". The cognitive fidelity as defined by Moyer-Packenham et al. ${ }^{[14]}$ is how well the math virtual tools reflect the user's cognitive actions while using them. While the cognitive fidelity as defined by Bos ${ }^{[33]}$ is the concept better understood when the virtual object is acted on, it makes sense and 
adds depth of understanding and meaningful strategy to the concept, because of the action performed on it. However, Mayer ${ }^{[34]}$ stated that the "generative cognitive processing occurs when a learner engages in deep processing in working memory in service of the learning goal, such as organizing the material and integrating it with prior knowledge".

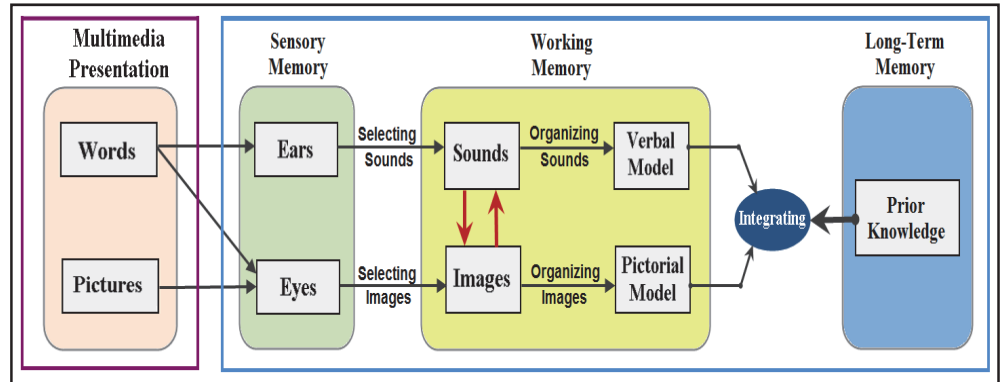

Fig. 5. Mayers' cognitive theory of multimedia learning model (Mayer, 2001).

\subsection{Cognitive Model of VR Learning}

Osberg $^{[35]}$ examined the relationship and distinction between multimedia and virtuality, he stated that VR goes at least one level above multimedia in terms of perceptual richness. The concept of virtuality plays an important role for cognition and knowledge acquisition, where it's likely to mimic and explore knowledge and receive an immediate feedback about the relevance of possible actions on the environment without ever having to leave the realm of virtuality ${ }^{[36]}$. Virtual education environments centers on the involvement of learners, not only in terms of real-time graphics and manipulation, but rather in terms of content, i.e. knowledge acquisition and the process of knowledge transfer ${ }^{[37]}$.

Hence, VR environments have key features of immersion, navigation, and interaction ${ }^{[7]}$. Thereby, we extend Mayers' cognitive theory of multimedia learning to suit virtual reality learning environments, by including a third channel 'Perceptual' for handling 'Perceptions', as shown in Fig. 6. As we can see from Fig. 3, the learning environment in this model is desktop VR learning environment, where the kind of interaction and perception that the user could perceive actually differs from multimedia. On the other hand, the student constructs new knowledge by integrating prior knowledge with his current experience within VR learning environments, this new knowledge according to Johnson et al. ${ }^{[38]}$ is a mapping of a novel system onto an already familiar one, this is what happens in long-term memory 
where new knowledge is incorporated with prior knowledge to form again new knowledge and so on. We suggest that students can be viewed as a knowledge constructor who actively selects and constructs pieces of verbal, visual and perceptual knowledge in unique ways.

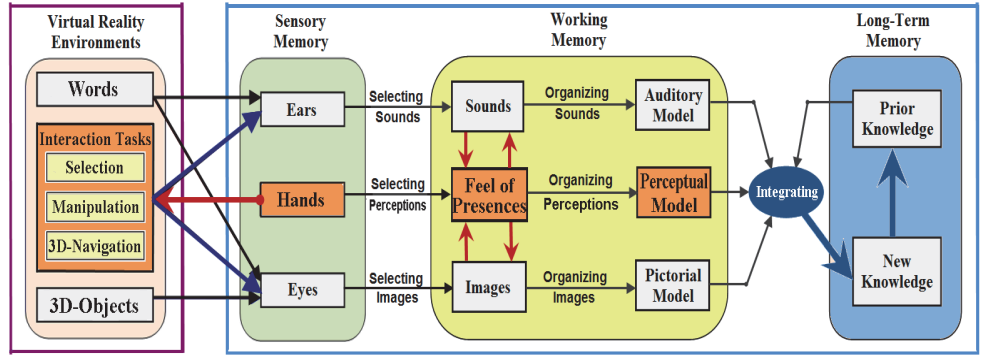

Fig. 6. Suggested detailed components of cognitive VR learning model.

Table 1 shows a complete comparison between Mayer's cognitive theory of multimedia learning model and the suggested cognitive theory of virtual reality learning model. As we can see from Table 1, the main difference between models is because of the VR distinct attributes of interaction tasks. The sensory memory acts as a processing system and the output will be as an input to the working memory. The working memory will organize the processed information in specific orders that formulate mental models. Finally the output from working memory will act as an input to the long-term memory. The output from the integration is an accumulated knowledge that represents the total knowledge gained due to cognitive VR information processing. New knowledge stored in long-term memory will act as a prior knowledge in the next cognitive information processing cycle.

Table 1. Cognitive model of Multimedia learning vs. suggested cognitive model of VR.

\begin{tabular}{|c|c|c|c|c|c|c|c|c|c|}
\hline \multirow{3}{*}{ 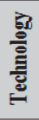 } & \multirow{3}{*}{ 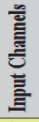 } & \multicolumn{8}{|c|}{ Cognitive Information Processing } \\
\hline & & \multicolumn{3}{|c|}{ Sensory Memory } & \multicolumn{3}{|c|}{ Working Memory } & \multicolumn{2}{|c|}{ Long-Term Memory } \\
\hline & & Sensor & Processing & Output & Input & Processing & Output & Input \& Integration & Output \\
\hline \multirow{2}{*}{ 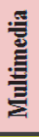 } & 旁 & Ears & $\begin{array}{l}\text { Selecting } \\
\text { Sounds }\end{array}$ & Sounds & Sounds & \multirow{2}{*}{ Organizing } & Auditory & \multirow{2}{*}{\begin{tabular}{|c|} 
Auditory Model \\
+ \\
Prior knowledge \\
+ \\
PictorialModel
\end{tabular}} & \multirow{2}{*}{$\begin{array}{l}\text { Accumulated } \\
\text { knowledge }\end{array}$} \\
\hline & $\overline{\underline{3}}$ & Eyes & $\begin{array}{c}\text { Selecting } \\
\text { Images }\end{array}$ & Images & Images & & \begin{tabular}{|l|} 
Pictorial \\
Model
\end{tabular} & & \\
\hline \multirow{3}{*}{ 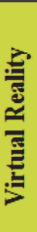 } & 搒 & Ears & $\begin{array}{l}\text { Selecting } \\
\text { Sounds }\end{array}$ & Sounds & Sounds & \multirow{3}{*}{ Organizing } & \begin{tabular}{|l|} 
Auditory \\
Model
\end{tabular} & \multirow{3}{*}{\begin{tabular}{|c|} 
AuditoryModel \\
+ \\
Prior knowledge \\
+ \\
Perceptual Model \\
+ \\
Pictorial Model
\end{tabular}} & \multirow{3}{*}{$\begin{array}{c}\text { Accumulated } \\
\text { knowledge } \\
+ \\
\text { New } \\
\text { knowledge }\end{array}$} \\
\hline & 플 & Hands & $\begin{array}{c}\text { Selecting } \\
\text { Perceptions }\end{array}$ & Perceptions & $\begin{array}{c}\text { Feel } \\
\text { Of } \\
\text { Presences }\end{array}$ & & $\begin{array}{l}\text { Perceptual } \\
\text { Model }\end{array}$ & & \\
\hline & 플 & Eyes & $\begin{array}{l}\text { Selecting } \\
\text { Images }\end{array}$ & Images & Images & & $\begin{array}{l}\text { Pictorial } \\
\text { Model }\end{array}$ & & \\
\hline
\end{tabular}




\section{Experimental Evaluation of VRMM vs. NLVM}

\subsection{Experimental Objectives}

In this experiment, several statistical case studies are investigated, to see the effectiveness of the VRMM learning experience compared with the NLVM. Eight case studies will be discussed. The study explores in-depth students' individual mathematical records from two perspectives: their individual math achievement level (Good or Excellent) and their classroom behavior (Quiet or Active). Students are categorized as shown in Table 2.

Table 2. Students sample demography based on their math record.

\begin{tabular}{|l|l|c|c|}
\hline Math Record & Description & $\mathrm{N}$ & Percent \\
\hline Good-Quiet & $\begin{array}{l}\text { Good = Math achievement level } \\
\text { Quiet = Classroom behavior }\end{array}$ & 29 & $27.9 \%$ \\
\hline Good-Active & $\begin{array}{l}\text { Good = Math achievement level } \\
\text { Active = Classroom behavior }\end{array}$ & 25 & $24.0 \%$ \\
\hline Excellent-Quiet & $\begin{array}{l}\text { Excellent = Math achievement level } \\
\text { Quiet = Classroom behavior }\end{array}$ & 26 & $25.0 \%$ \\
\hline Excellent-Active & Excellent = Math achievement level & 24 & $23.1 \%$ \\
\cline { 2 - 4 } & Active = Classroom behavior & &
\end{tabular}

An investigation is performed in order to answer this question: Do students' addition and subtraction learning experience differ according to their achievement level and classroom behavior? The target sample used is the 2nd grade students aged between seven and eight years, selected from four private elementary girl schools in western-central Jeddah, in Saudi Arabia. A total of 104 students are included in this study. Students are randomly assigned to either the NLVM or VRMM math VM learning environment.

\subsection{Data Collection}

The computer lab setting is prepared by the researcher by placing a numbered sticker on each computer screen. This number is linked with the name of each student listed on the class register in order to define the student's place in the computer lab. Data is collected using a Screen Video Capturing Program CamStudio released by a company called RenderSoft (http://camstudio.org/). The flexible nature of this screen video-based data collection facilitates a researcher to rewind and review material repeatedly. This CamStudio software is used to record on-screen student activity and their interaction during the experimental computer lab sessions. The recorded screens video for all students was carefully 
analyzed for all relevant aspects of the addition and subtraction concepts as defined in Table 3 and Table 4.

Table 3. Description of dependent Exercises variables.

\begin{tabular}{|l|l|}
\hline Exercises & Description \\
\hline Solved & $\begin{array}{l}\text { Represents the total number of successfully completion for addition and } \\
\text { subtraction exercises. }\end{array}$ \\
\hline Unsolved & $\begin{array}{l}\text { Represents the total number of unsuccessfully completion of addition and } \\
\text { subtraction exercises. }\end{array}$ \\
\hline Total & Represent the total number of all (successful and unsuccessful) exercises. \\
\hline
\end{tabular}

Table 4. Description of dependent Operational Errors variables.

\begin{tabular}{|l|l|}
\hline Operational Errors & Description \\
\hline Carry & $\begin{array}{l}\text { Represent the total number of errors done while performing the carry } \\
\text { concept operation. }\end{array}$ \\
\hline Borrow & $\begin{array}{l}\text { Represent the total number of errors done while performing the } \\
\text { borrow operation. }\end{array}$ \\
\hline Place-Value & $\begin{array}{l}\text { Represents the total number of errors done while moving base-10 } \\
\text { blocks between place values (i.e. units, tens, and hundreds). }\end{array}$ \\
\hline
\end{tabular}

\section{Results and Discussions}

The statistical analysis of the data collected from the study samples are achieved using the "Statistical Package for the Social Sciences" (Spss, 2008). We compared the statistical variables means by conducting an independent sample t-test. The statistical significance (p-level) of a result is used as an estimated measure of the degree of acceptance. Results that yield $\mathrm{p} \leq 0.05$ are considered borderline statistically significant, but this level of significance still involves a quite high probability of error $(5 \%)$. Results that are significant at the $p \leq 0.01$ level are commonly considered statistically significant, and $\mathrm{p} \leq 0.005$ or $\mathrm{p} \leq 0.001$ levels are often called "highly" significant. The following case studies will investigate and compare between the mathematical virtual Manipulatives VRMM, and NLVM to find out their learning effects on mathematical concepts including addition and subtraction operations.

\subsection{Case Study-1: Good-Quiet students Exercises comparison between NLVM and VRMM}

Table 5 presents t-tests for exercises variables. We notice that the mean value of Solved exercises within VRMM is statistically significant since $p<0.01$, where the mean of VRMM is greater than mean of NLVM. For Unsolved exercises, the mean difference between NLVM and VRMM is not statistically significant since $p>0.05$. The mean 
difference between NLVM and VRMM for the Total mean value of exercises are approaching statistically significance since $p=0.05$, where the mean of VRMM is greater than mean of NLVM.

Table 5. Good-Quiet students mean number of Exercises for NLVM (n=17) and VRMM $(\mathbf{n}=12)$.

\begin{tabular}{|c|c|c|c|c|c|c|}
\hline \multirow[b]{2}{*}{ Exercises } & \multirow[b]{2}{*}{ Statistics } & \multirow[b]{2}{*}{ NLVM } & \multirow[b]{2}{*}{ VRMM } & \multicolumn{3}{|c|}{ t-test for Equality of Means } \\
\hline & & & & $t$ & $d f$ & $\begin{array}{l}\text { Sig.(2-tailed) p- } \\
\text { value }\end{array}$ \\
\hline \multirow{2}{*}{ Solved } & Mean & 6.35 & 11.42 & \multirow{2}{*}{-2.916} & \multirow{2}{*}{27} & \multirow{2}{*}{$0.007^{* *}$} \\
\hline & SD & 3.904 & 5.468 & & & \\
\hline \multirow{2}{*}{ Unsolved } & Mean & 4.41 & 4.08 & \multirow{2}{*}{0.227} & \multirow{2}{*}{27} & \multirow{2}{*}{0.822} \\
\hline & SD & 4.417 & 2.778 & & & \\
\hline \multirow{2}{*}{ Total } & Mean & 10.76 & 15.50 & \multirow{2}{*}{-2.037} & \multirow{2}{*}{27} & \multirow{2}{*}{0.052} \\
\hline & SD & 6.350 & 5.885 & & & \\
\hline
\end{tabular}

$* *$ Indicates $\mathrm{p} \leq 0.01, *$ Indicates $\mathrm{p} \leq 0.05$.

\subsection{Case Study-2: Good-Active students Exercises comparison between NLVM and VRMM}

For the mean value of Solved, Unsolved and Total exercises, Table 6 shows that the difference between NLVM and VRMM is not statistically significant since $\mathrm{p}>0.05$.

Table 6. Good-Active students mean number of Exercises for NLVM (n=12) and VRMM $(n=13)$.

\begin{tabular}{|c|c|c|c|c|c|c|}
\hline \multirow[b]{2}{*}{ Exercises } & \multirow[b]{2}{*}{ Statistics } & \multirow[b]{2}{*}{ NLVM } & \multirow[b]{2}{*}{ VRMM } & \multicolumn{3}{|c|}{ t-test for Equality of Means } \\
\hline & & & & $t$ & $d f$ & $\begin{array}{l}\text { Sig.(2-tailed) } \\
\text { p-value }\end{array}$ \\
\hline \multirow{2}{*}{ Solved } & Mean & 6.92 & 7.08 & \multirow{2}{*}{-0.100} & \multirow{2}{*}{23} & \multirow{2}{*}{0.921} \\
\hline & SD & 3.825 & 4.132 & & & \\
\hline \multirow{2}{*}{ Unsolved } & Mean & 5.42 & 3.08 & \multirow{2}{*}{1.874} & \multirow{2}{*}{23} & \multirow{2}{*}{0.074} \\
\hline & SD & 3.370 & 2.871 & & & \\
\hline \multirow{2}{*}{ Total } & Mean & 12.33 & 10.15 & \multirow{2}{*}{1.283} & \multirow{2}{*}{23} & \multirow{2}{*}{0.212} \\
\hline & SD & 4.376 & 4.120 & & & \\
\hline
\end{tabular}

\subsection{Case Study-3: Excellent-Quiet students Exercises comparison between NLVM and VRMM}

Table 7 presents t-tests for exercises variables. We notice that the mean value of Solved exercises within VRMM is approaching statistically significance since $p=0.05$, where the mean of VRMM is greater than mean value of NLVM. For Unsolved and Total exercises, the mean difference between NLVM and VRMM is not statistically significant since $p>0.05$, even though the mean of VRMM is greater than mean value of NLVM. 
Table 7. Excellent-Quiet students mean number of Exercises for NLVM (n=9) and VRMM $(n=17)$.

\begin{tabular}{|c|c|c|c|c|c|c|}
\hline \multirow[b]{2}{*}{ Exercises } & \multirow[b]{2}{*}{ Statistics } & \multirow[b]{2}{*}{ NLVM } & \multirow[b]{2}{*}{ VRMM } & \multicolumn{3}{|c|}{ t-test for Equality of Means } \\
\hline & & & & $t$ & $d f$ & $\begin{array}{l}\text { Sig. (2-tailed) P- } \\
\text { value }\end{array}$ \\
\hline \multirow{2}{*}{ Solved } & Mean & 6.67 & 12.29 & \multirow{2}{*}{-2.064} & \multirow{2}{*}{24} & \multirow{2}{*}{$0.050^{*}$} \\
\hline & SD & 3.279 & 7.760 & & & \\
\hline \multirow{2}{*}{ Unsolved } & Mean & 3.78 & 2.29 & \multirow{2}{*}{1.704} & \multirow{2}{*}{24} & \multirow{2}{*}{0.101} \\
\hline & SD & 2.774 & 1.687 & & & \\
\hline \multirow{2}{*}{ Total } & Mean & 10.44 & 14.59 & \multirow{2}{*}{-1.478} & \multirow{2}{*}{24} & \multirow{2}{*}{0.152} \\
\hline & SD & 4.447 & 7.714 & & & \\
\hline
\end{tabular}

*Indicates $\mathrm{p} \leq 0.05$.

\subsection{Case Study-4: Excellent-Active students Exercises comparison between NLVM and VRMM}

Table 8 presents t-tests for exercises variables. We notice that the mean value of Solved exercises within VRMM is statistically significant since $\mathrm{p}<0.05$, where the mean of VRMM is greater than mean of NLVM. For Unsolved exercises, the mean difference between NLVM and VRMM is not statistically significant since $\mathrm{p}>0.05$. The mean difference between NLVM and VRMM for the Total exercises is statistically significance since $p<0.05$, where the mean of VRMM is greater than mean of NLVM.

Table 8. Excellent-Active students mean number of Exercises for NLVM $(n=14)$ and $\operatorname{VRMM}(\mathbf{n}=10)$.

\begin{tabular}{|c|c|c|c|c|c|c|}
\hline \multirow[b]{2}{*}{ Exercises } & \multirow[b]{2}{*}{ Statistics } & \multirow[b]{2}{*}{ NLVM } & \multirow[b]{2}{*}{ VRMM } & \multicolumn{3}{|c|}{ t-test for Equality of Means } \\
\hline & & & & $t$ & $d f$ & $\begin{array}{l}\text { Sig. (2-tailed) p- } \\
\text { value }\end{array}$ \\
\hline \multirow{2}{*}{ Solved } & Mean & 7.36 & 12.50 & \multirow{2}{*}{-2.671} & \multirow{2}{*}{22} & \multirow{2}{*}{$0.014^{*}$} \\
\hline & SD & 3.296 & 6.096 & & & \\
\hline \multirow{2}{*}{ Unsolved } & Mean & 4.00 & 3.30 & \multirow{2}{*}{0.961} & \multirow{2}{*}{22} & \multirow{2}{*}{0.347} \\
\hline & SD & 2.000 & 1.337 & & & \\
\hline \multirow{2}{*}{ Total } & Mean & 11.36 & 15.80 & \multirow{2}{*}{-2.110} & \multirow{2}{*}{22} & \multirow{2}{*}{$0.046^{*}$} \\
\hline & SD & 3.201 & 6.957 & & & \\
\hline
\end{tabular}

*Indicates $\mathrm{p} \leq 0.05$.

\subsection{Case Study-5: Good-Quiet students Operational Errors comparison between NLVM and VRMM}

Table 9 presents t-tests for operational errors variables. We notice that the mean value of Carry errors within VRMM is statistically significance since $\mathrm{p}<0.05$, where the mean of VRMM is less than mean 
value of NLVM. For Borrow and Place-value errors, the mean difference between NLVM and VRMM is not statistically significant since $p>0.05$, even though the mean of VRMM is less than mean value of NLVM.

Table 9. Good-Quiet students mean number of Operational Errors for NLVM ( $n=17)$ and $\operatorname{VRMM}(\mathrm{n}=12)$.

\begin{tabular}{|c|c|c|c|c|c|c|}
\hline \multirow{2}{*}{$\begin{array}{l}\text { Operational } \\
\text { Errors }\end{array}$} & \multirow[b]{2}{*}{ Statistics } & \multirow[b]{2}{*}{ NLVM } & \multirow[b]{2}{*}{ VRMM } & \multicolumn{3}{|c|}{ t-test for Equality of Means } \\
\hline & & & & $t$ & $d f$ & $\begin{array}{l}\text { Sig.(2-tailed) p } \\
\text { value }\end{array}$ \\
\hline \multirow{2}{*}{ Carry } & Mean & 2.94 & 1.33 & \multirow{2}{*}{2.136} & \multirow{2}{*}{27} & \multirow{2}{*}{$0.042 *$} \\
\hline & $\mathrm{SD}$ & 2.277 & 1.497 & & & \\
\hline \multirow{2}{*}{ Borrow } & Mean & 2.12 & 0.58 & \multirow{2}{*}{1.822} & \multirow{2}{*}{27} & \multirow{2}{*}{0.080} \\
\hline & SD & 2.759 & 1.084 & & & \\
\hline \multirow{2}{*}{ Place-Value } & Mean & 2.06 & 1.17 & \multirow{2}{*}{0.941} & \multirow{2}{*}{27} & \multirow{2}{*}{0.355} \\
\hline & SD & 3.030 & 1.467 & & & \\
\hline
\end{tabular}

*Indicates $\mathrm{p} \leq 0.05$.

\subsection{Case Study-6: Good-Active students Operational Errors comparison between (NLVM, VRMM)}

Table 10 presents t-tests for operational errors variables. We notice that the mean value of Carry errors within VRMM is statistically significant since $\mathrm{p}<0.01$, where the mean of VRMM is less than mean of NLVM. For Borrow errors, the mean difference between NLVM and VRMM is statistically significant since $p<0.01$, where the mean of VRMM is less than mean of NLVM. However, the mean difference between NLVM and VRMM for the Place-Value errors is statistically significance since $\mathrm{p}<0.05$, where the mean of VRMM is less than mean of NLVM.

Table 10. Good-Active students mean number of Operational Errors for NLVM $(n=12)$ and $\operatorname{VRMM}(n=13)$.

\begin{tabular}{llllllll}
\hline \multirow{2}{*}{$\begin{array}{l}\text { Operational } \\
\text { Errors }\end{array}$} & Statistics & NLVM & VRMM & \multicolumn{2}{c}{ t-test for Equality of Means } \\
\cline { 6 - 7 } Carry & Mean & 4.75 & 0.31 & & $\boldsymbol{d}$ ff & $\begin{array}{l}\text { Sig. (2-tailed) } \\
\text { P-value }\end{array}$ \\
& SD & 4.770 & 0.630 & 3.333 & 23 & $0.003^{* *}$ \\
Borrow & Mean & 3.58 & 0.38 & & & \\
& SD & 3.450 & 0.768 & 3.262 & 23 & $0.003^{* *}$ \\
Place-Value & Mean & 3.25 & 1.00 & & & \\
& SD & 3.108 & 1.780 & 2.244 & 23 & $0.035^{*}$ \\
\hline
\end{tabular}

$* *$ Indicates $\mathrm{p} \leq 0.01, *$ Indicates $\mathrm{p} \leq 0.05$. 


\subsection{Case Study-7: Excellent-Quiet students Operational Errors comparison between (NLVM, VRMM)}

Table 11 presents t-tests for operational errors variables. We notice that the mean value of Carry errors within VRMM is statistically significant since $\mathrm{p}<0.01$, where the mean of VRMM is less than mean of NLVM. For Borrow and Place-Value errors, the mean difference between NLVM and VRMM is statistically not significant since $\mathrm{p}>0.05$.

Table 11. Excellent-Quiet students mean number of Operational Errors for NLVM (n=9) and VRMM $(n=17)$.

\begin{tabular}{|c|c|c|c|c|c|c|}
\hline \multirow{2}{*}{$\begin{array}{l}\text { Operational } \\
\text { Errors }\end{array}$} & \multirow[b]{2}{*}{ Statistics } & \multirow[b]{2}{*}{ NLVM } & \multirow[b]{2}{*}{ VRMM } & \multicolumn{3}{|c|}{ t-test for Equality of Means } \\
\hline & & & & $t$ & $d f$ & $\begin{array}{l}\text { Sig. (2-tailed) p- } \\
\text { value }\end{array}$ \\
\hline \multirow{2}{*}{ Carry } & Mean & 3.44 & 0.82 & \multirow{2}{*}{3.705} & \multirow{2}{*}{24} & \multirow{2}{*}{$0.001 * *$} \\
\hline & SD & 2.555 & 1.074 & & & \\
\hline \multirow{2}{*}{ Borrow } & Mean & 1.00 & 0.41 & \multirow{2}{*}{1.423} & \multirow{2}{*}{24} & \multirow{2}{*}{0.167} \\
\hline & $\mathrm{SD}$ & 1.414 & 0.712 & & & \\
\hline \multirow{2}{*}{ Place-Value } & Mean & 1.11 & 1.35 & \multirow{2}{*}{-.450} & \multirow{2}{*}{24} & \multirow{2}{*}{0.657} \\
\hline & SD & 1.453 & 1.222 & & & \\
\hline
\end{tabular}

$* *$ Indicates $\mathrm{p} \leq 0.01$.

\subsection{Case Study-8: Excellent-Active students Operational Errors comparison between (NLVM, VRMM)}

Table 12 presents t-tests for operational errors variables. We notice that the mean value of Carry errors within VRMM is statistically significant since $\mathrm{p}<0.05$, where the mean of VRMM is less than mean of NLVM. For Borrow errors, the mean difference between NLVM and VRMM is not statistically significant since $\mathrm{p}>0.05$, even though the mean of VRMM is less than mean value of NLVM. However, for PlaceValue errors, the mean difference between NLVM and VRMM is statistically not significant since $\mathrm{p}>0.05$.

Table 12. Excellent-Active students mean number of Exercises for NLVM $(n=14)$ and $\operatorname{VRMM}(\mathrm{n}=10)$.

\begin{tabular}{|c|c|c|c|c|c|c|}
\hline \multirow[b]{2}{*}{$\begin{array}{l}\text { Operational } \\
\text { Errors }\end{array}$} & \multirow[b]{2}{*}{ Statistics } & \multirow[b]{2}{*}{ NLVM } & \multirow[b]{2}{*}{ VRMM } & \multicolumn{3}{|c|}{ t-test for Equality of Means } \\
\hline & & & & $t$ & $d f$ & $\begin{array}{l}\text { Sig. (2-tailed) p- } \\
\text { value }\end{array}$ \\
\hline \multirow{2}{*}{ Carry } & Mean & 3.50 & 0.90 & \multirow{2}{*}{2.283} & \multirow{2}{*}{22} & \multirow{2}{*}{$0.032 *$} \\
\hline & SD & 3.525 & 0.738 & & & \\
\hline \multirow{2}{*}{ Borrow } & Mean & 1.36 & 0.50 & \multirow{2}{*}{1.625} & \multirow{2}{*}{22} & \multirow{2}{*}{0.118} \\
\hline & SD & 1.277 & 1.269 & & & \\
\hline \multirow{2}{*}{ Place-Value } & Mean & 1.71 & 2.00 & \multirow{2}{*}{-3.16} & \multirow{2}{*}{22} & \multirow{2}{*}{0.755} \\
\hline & SD & 2.128 & 2.261 & & & \\
\hline
\end{tabular}

*Indicates $\mathrm{p} \leq 0.05$. 


\subsection{Summary of Results}

Fig. 7 shows the relation between students' math recorders and mean numbers of exercises. This result indicates that the mean values of VRMM exceed the means values of NLVM for most case studies shown in the figure. Hence, the total number of correctly solved exercises while interacting with VRMM outperforms those in NLVM. Figure 8 shows the relation between students' math recorders and mean numbers of total errors. This result indicates that the mean values of VRMM are less than the means values of NLVM, indicating that student exercises with VRMM complain of fewer mistakes while solving exercises than those exercises with NLVM.

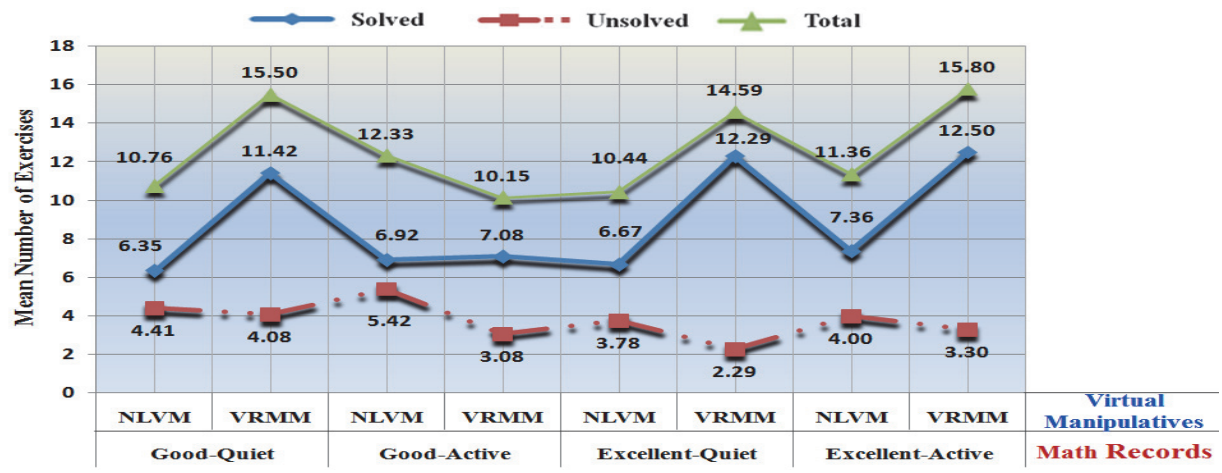

Fig. 7. Compare means of Exercises variables between NLVM and VRMM, based upon students' math records.

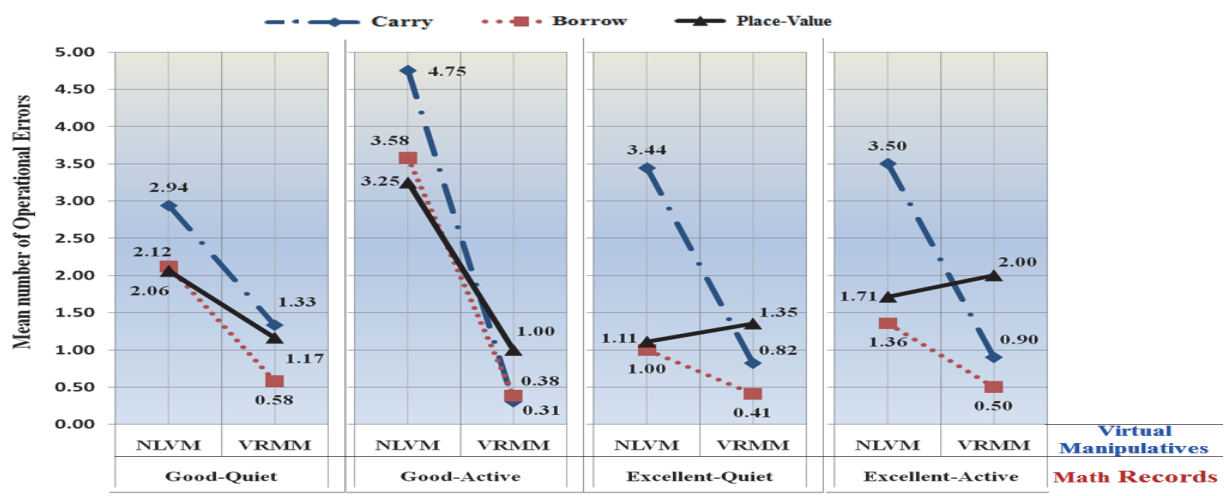

Fig. 8. Compare means of Operational Errors variables between NLVM and VRMM, based upon students' math records. 


\section{Conclusion}

In this paper virtual reality math manipulatives is explained. This is considering it as one of VR technology's powerful tool in educational application, enhancing learning experience to young students. A model for cognitive theory of virtual reality learning is presented, and is compared with the well known cognitive theory of multimedia learning by Mayer ${ }^{[30]}$. This VR model support the cognitive fidelity to prove how well the virtual tools reflect the user's cognitive actions and possible choices while using the tool in the virtual environment. The model emphasizes the important process of connecting numeracy concepts and relationships with symbols, rules and procedures that are used to represent and interact with VRMM. Experiment result show superiority in the learning development of young student while using VRMM, compared to Mayer's cognitive multimedia learning model that can be clearly seen in NLVM learning tools.

The learning experience gained using VRMM is more effective than NLVM. Since VRMM allows more realistic and detailed virtual manipulatives representations, offering free navigation and viewpoints for more inspection possibilities compared to NLVM. Through experiment the student learning interest and attention are improved on account of using the VRMM capabilities. Experiment results from this work enabled us to decipher that students from the category Good-Quiet and Excellent-Quiet were the most engaged with VRMM compared to those students from the Good-Active and Excellent Active categories. The reason for this improvement is clearly associated with students who share the Quiet classroom behavior regardless of their math achievement level. The study also emphasizes that the VRMM is capable of engaging and enhancing Quiet students and influencing them to interact regardless of any inhibitions.

\section{References}

[1] M. Roussou, "Learning by doing and learning through play: an exploration of interactivity in virtual environments for children," ACM Computers in Entertainment, 2: 1-23, (2004).

[2] L. Quan, et al., "Three-dimensional virtual chemical laboratory based on virtual reality modeling language," presented at the IT in Medicine and Education, ITME. IEEE International Symposium on, (2008).

[3] H. Tüzün, et al., "The effects of computer games on primary school students' achievement and motivation in geography learning," Computers \& Education, 52: 68-77, (2009). 
[4] J. W. Juhnke and A. R. Kallish, "Adaptive learning via social cognitive theory and digital cultural ecosystems." vol. 5638 LNAI, ed San Diego, CA, United states: Springer Verlag, 2009, pp. 611-619.

[5] M. R. Stytz and S. B. Banks., Requirements for Distributed Virtual Environments for Medical Training and Education. Available: http://www.siaa.asn.au/get/24100- 78840.pdf. (2008).

[6] J. G. Tichon, "Using presence to improve a virtual training environment," Cyberpsychology \& Behavior, 10 (Dec): 781-787, (2007).

[7] J. K. Crosier, et al., "Key lessons for the design and integration of virtual environments in secondary science," Computers \& Education, 38: 77-94, (2002).

[8] E. Lee and K. Wong, "A review of using virtual reality for learning," Transactions on edutainment I, pp: 231-241, (2008).

[9] P. S. Moyer, et al., "Virtual Manipulatives in the K-12 Classroom," presented at the International Conference on New Ideas in Mathematics Education, (2001).

[10] T. A. Herrera, "The Internet as Instructional Tool: A Consideration of Its Potential Role in the Elementary Mathematics Classroom," presented at the The Mathematics Education into the 21st Century Project, Proceedings of the International Conference "The Decidable and the Undecidable in Mathematics Education", Brno, Czech Republic, (2003).

[11] P. S. Moyer, et al., "What Are Virtual Manipulatives?," Teaching Children Mathematics, 8: 372-377, (2002).

[12] R. B. Singapogu and T. C. Burg, "Haptic virtual manipulatives for enhancing K-12 special education," presented at the $47^{\text {th }}$ Annual Southeast Regional Conference, ACM-SE 47, March 19-21, Clemson, SC, United states, (2009).

[13] K. Reimer and P. S. Moyer, "Third-graders learn about fractions using virtual manipulatives: A classroom study," Journal of Computers in Mathematics and Science Teaching, 24: 5-25, (2005).

[14] P. S. Moyer-Packenham, et al., "Virtual manipulatives used by K-8 teachers for mathematics instruction: Considering mathematical, cognitive, and pedagogical fidelity," Contemporary Issues in Technology and Teacher Education, 8: 202-218, (2008).

[15] J. Bolyard and P. Moyer-Packenham, "The impact of virtual manipulatives on student achievement in integer addition and subtraction," presented at the PME-NA 2006 Conference, Mérida, México: Universidad Pedagógica Nacional, (2006).

[16] R. Yun, et al., "Using VRML and JAVA to build virtual game-based learning environment for addition and subtraction operation." LNCS, ed Penang, Malaysia: Springer Verlag, 4181: 146-153, (2006).

[17] L. Daghestani, et al., "The Design, Development and Evaluation of Virtual Reality Learning Environment for Numeracy Concepts Using 3D Virtual Manipulatives," presented at the Fifth International Conference on Computer Graphics, Imaging and Visualisation, CGIV '08, (2008).

[18] A. d. S. Figueira-Sampaio, et al., "A constructivist computational tool to assist in learning primary school mathematical equations," Computers \& Education, 53: 484-492, (2009).

[19] M. Roussou, "A VR Playground for Learning Abstract Mathematics Concepts," Computer Graphics and Applications, IEEE, 29: 82-85, (2009).

[20] L. Daghestani, et al., "Virtual reality potential role in numeracy concepts using virtual manipulatives," presented at the Advances in Computer Science and Engineering: Proceedings of the Sixth IASTED International Conference (ACSE) (2010).

[21] L. Daghestani, et al., "Cognitive theory of Virtual Reality learning for Evaluating Virtual Manipulatives," To be presented at International Journal of Human-Computer Studies, press.

[22] D. H. Jonassen, "Thinking Technology: Toward a constructivist design model," Educational Technology,34: 34-37, (1994). 
[23] D. H. Jonassen and M. Tessmer, "An outcomes-based taxonomy for instructional systems design, evaluation, and research," Training Research Journal, 2: 11-46, (1996/97).

[24] Z. P. Dienes, "Some Thoughts on The Dynamics of Learning Mathematics," in The Montana Mathematics Enthusiast-Monograph Series in Mathematics Educaton, B. Sriraman, Ed., ed Missoula, Montana, USA: Information Age Publishing and the Department of Mathematical Sciences-The University of Montana, pp: 1-118 (2007).

[25] R. Parasuraman, et al., "A model for types and levels of human interaction with automation," IEEE TRANSACTIONS ON SYSTEMS, MAN, AND CYBERNETICS - PART A: SYSTEMS AND HUMANS, 30: 286-297, (2000).

[26] D. Nunez, "A constructionist cognitive model of virtual presence," presented at the $7^{\text {th }}$ International Workshop on Presence (PRESENCE), Valencia, Spain, (2004).

[27] C. D. Wickens, Engineering psychology and human performance. New York: HarperCollins, (1992).

[28] A. Paivio, Mental representations: A dual coding approach. New York: Oxford University Press, (1990).

[29] J. Sweller, Instructional design in technical areas. Camberwell, Australia: ACER, (1999).

[30] R. E. Mayer, Multimedia Learning. New York: Cambridge University Press, (2001).

[31] B. M. McLaren, et al., "Polite web-based intelligent tutors: Can they improve learning in classrooms?," Computers \& Education, 56: 574-584, (2011).

[32] B. M. McLaren, et al., "A politeness effect in learning with web-based intelligent tutors," International Journal of Human-Computer Studies, 69: 70-79, (2011).

[33] B. Bos, "Virtual math objects with pedagogical, mathematical, and cognitive fidelity," Computers in Human Behavior, 25: 521-528, (2009).

[34] R. E. Mayer, Ed., The Cambridge handbook of multimedia learning. Cambridge: Cambridge University Press, (2005).

[35] K. M. Osberg., Constructivism in practice: the case for meaning-making in the virtual world [A dissertation submitted in partial fulfillment of the requirements for the degree of Doctor of Education]. Available: http://www.hitl.washington. edu/publications/r-9747/title.html (1997).

[36] M. P. Peschl and A. Riegler, " Virtual Science. Virtuality and Knowledge Acquisition in Science and Cognition," in Virtual Reality. Cognitive Foundations, Technological Issues, and Philosophical Implications, A. In: Riegler, Peschl, M., Edlinger, K., Fleck, G. \& Feigl, W. (eds.), Ed., ed: Peter Lang Verlag: Frankfurt/M., pp: 9-32 (2001).

[37] C. Stary, "Exploring the Concept of Virtuality: Technological Approaches and Implications from Tele-Education," presented at the Virtual Reality: Cognitive Foundations, Technological Issues \& Philosophical Implications, (2001).

[38] A. Johnson, et al., "Exploring multiple representations in elementary school science education," presented at the Virtual Reality, Proceedings. IEEE, (2001). 
نموذج تفاعلي في التعليم الواقع الافتراضي لتقويم أداء طرق

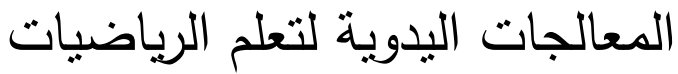

لمياء داغستاني +، "، وهناء النعيم+، وزهجي زو"، وعبدالحميد رجب+

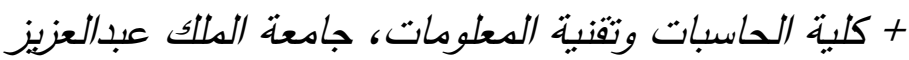
جدة، المدلكة العربية السعودية *كلبة الحاسبات والهندسة، جامعة هدرفيلد، هدرزفيلد، المدلكة المتحدة

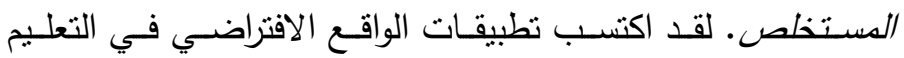

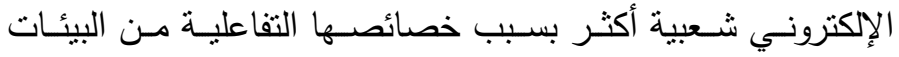
الافتراضية التي يمكن تقديمها. وهناك مثال فريد من نوعه من هذائها

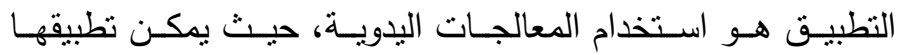

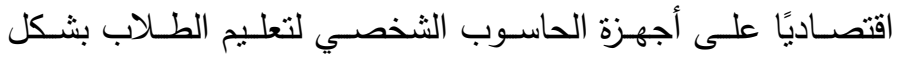
تفاعلي في المدارس والجامعات. فهي تمكن الطلاب لتعلم الرياضيات

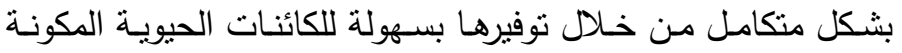

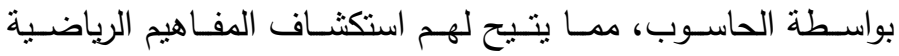

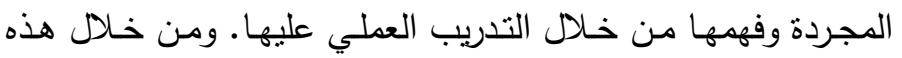

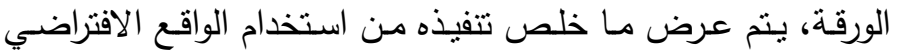

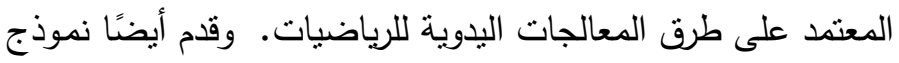

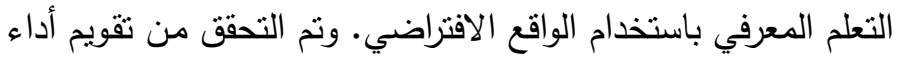

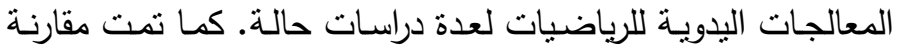
بين استخدام بعدين من تطبيقات جافا من المكتبة الوطنية الافتراضية

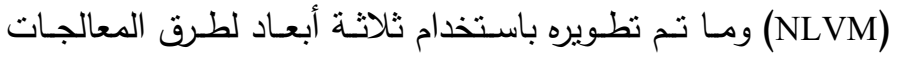

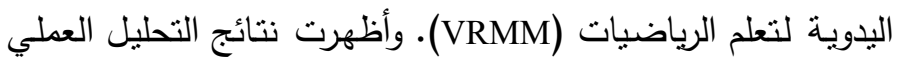

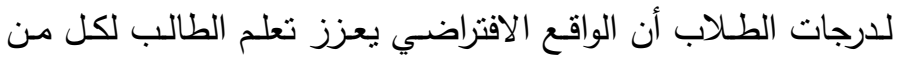

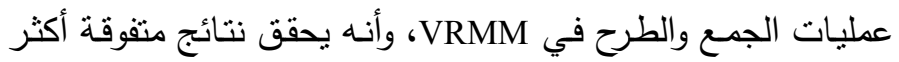
منها في NLVM. 